COLUMN

\title{
Pension contributions from April 2019
}

\section{BDA Head of Pensions, Phil McEvoy,} on what employers and employees need to know from 1 April

Automatic enrolment requires practice owners to place practice employees into a workplace pension scheme. This ensures increased levels of pension saving in the UK. The requirement was gradually introduced over a period of five years, and since March 2018, every UK employer must comply. Both employee and employer have a duty to pay a minimum level of pension contributions. The minimum level of contributions is set to rise from 1 April 2019 meaning that:

$\rightarrow$ Employers will have to pay a minimum of $3 \%$ of qualifying earnings ( $2 \%$ before April 2019)

$\rightarrow$ Employees will have to pay a minimum of $4 \%$ of qualifying earnings ( $2.6 \%$ before April 2019)

$\rightarrow$ Government will add an additional 1\% of qualifying earnings in tax relief $(0.4 \%$ before April 2019).

Qualifying earnings represent all taxable earnings between $£ 6,136$ and $£ 50,000$ per annum (for the 2019/20 tax year). Employers can set up pension schemes which levy contributions on all income, provided that the above minimum standard is met.

This represents the last of the phased increases to minimum pension contributions, although these rates are likely to be reviewed in the future. The definition of qualifying earnings is likely to change in future tax years.

\section{NHS Pension} Scheme Employer Contributions The NHS has partially completed a review into the costs of paying for the benefits promised under the NHS Pension Scheme. Due to a downgrading in HM Treasury's growth forecast for the future, the cost of providing the NHS Pension Scheme is set to significantly increase from April 2019. These cost rises will fall on employers meaning that their contributions will rise to $20.6 \%$ of earnings (England and Wales), $20.9 \%$ (Scotland) and $22.5 \%$ (Northern Ireland). The UK Government pre-empted this rise in the June 2018 five-year NHS funding plan, which saw money allocated for this purpose. Most practices are not required to pay this cost, which is met directly by the NHS; however some dentistry services will have been commissioned on the basis that the contractor acts as the employer for the purposes of making pension contributions.

For England, the Department of Health and Social Care published a position on 4 March which gave clarification on the extension of funding to these employers. This states that full funding will be available for a range of bodies including NHS Trusts, General Dental Practitioners, Independent Providers, Social Enterprises and New Fair Deal employers (who have received a bulk transfer of employees). Limited funding will only be provided until March 2020 for Universities and Arm's Length Bodies, including NHS England, HEE, CQC, Public Health England, NHS Business Services and NHS Improvement.

At the time of writing no confirmation has been received in respect of the funding position in Wales, Scotland or Northern Ireland.

\section{NEWS FROM THE BDA}

Reallocation of NI GDS underspend 'putting Health Service dentistry at risk'

BDA Northern Ireland has hit back at the Health and Social Care Board on its recent decision to reallocate $£ 7.7 \mathrm{~m}$ of underspend away from the GDS budget to 'other budgets'.

In a letter to Dr Ian Clements, Chair of HSCB, the Chair of the BDA Northern Ireland Dental Practice Committee Richard Graham challenged the rationale provided by finance personnel to the HSCB's Board of Directors for the GDS underspend.

Richard said: 'GDPs are under incredible financial pressure, having seen taxable income decimated after 8 years of increased costs and constrained fee uplifts, as well as pay cuts. Advising board members the GDS budget is reducing because individuals are now 'choosing to be treated privately', and that this won't have any real impact because 'we don't have access issues' simply won't wash.

'It's not just the livelihoods of GDPs that suffers. The HSCB has also been put on notice that reallocating funds away from dentistry is contrary to the extra investment we need to see in addressing our poor oral health and huge level of unmet need, not least among the elderly population living in care home settings. By attending the February Board meeting in person, we had an opportunity to voice our concerns directly with the HSCB Chair, and to Board members.

'Our message to the HSCB and to the Department of Health at this time is that their actions - and inactions - are putting Health Service dentistry at considerable risk. Removing commitment payments worth over $£ 3$ m to GDPs a year, and failing to adequately address the rising costs of delivering HS dentistry with capped fee uplifts, plus a prior approval limit that's remained static for a decade has resulted in a fee structure that isn't fit for purpose.' 